\section{Smoking v. nicotine}

The distinction between smoking, which is a habit, and nicotine addiction often becomes blurred in the article by Schultz and colleagues ${ }^{1}$ and in the responses to it. That health professionals avoid this trap of convenience is important. Viewing smoking as addictive, which most of the population superficially does, plays directly into the hands of smokers' rights advocates and their claims that smoking bans are discriminatory. Remembering that smoking is a habit and that nicotine is addictive reminds us that there are many other forms in which nicotine can be delivered - even if less gratifying - without exposing others. Smokers can choose where and how to get their hit of nicotine - the rest of us can't choose where to breathe.

\section{Stuart H. Kreisman MD}

Endocrinologist, St. Paul's Hospital, Vancouver, BC

\section{Reference}

1. Schultz ASH, Finegan B, Nykiforuk CIJ, et al. A qualitative investigation of smoke-free policies on hospital property. CMAJ 2011;183:E1334-44.

CMAJ 2012. DOI:10.1503/cmaj.112-2010

\section{Care for smokers}

In an excellent article about two Canadian hospitals that are failing to provide effective and compassionate care for patients who smoke, Schultz and colleagues ${ }^{1}$ note that many patients do not have access to nicotine replacement therapy and must risk leaving the hospital grounds to smoke.

"No smoking" policies are effective in places that smokers can choose to avoid (e.g., restaurants) or to visit only for a short time (e.g., banks), but such policies are inappropriate for hospitals, where smokers may be confined for days. Simplistic smoking bans seem ineffective and punitive. Many smokers are addicted to tobacco and cannot quit without assistance.

Hospitals need safe, well-ventilated, designated smoking areas for inpatients. These areas should include centres that offer treatment for tobacco addiction and provide helpful resources that could include the following:

- Televisions (with multilingual audio tracks and subtitles) looping information and inspirational messages from smokers who have quit

- Posters, booklets and pamphlets about smoking cessation

- Telephone hotlines to the Smokers' Helpline and to a hospital resource person, perhaps a pharmacist, who could ensure 24/7 access to nicotine replacement and could arrange an appointment with a smoking cessation counsellor

- Dispensing machines for nicotine replacement products

- Computers with access to smoking cessation resources

If such changes were to be implemented, we could consider ourselves health care workers who are treating patients for addiction. Until then, we are acting as sadistic jailers of innocent victims of the tobacco industry.

\section{John Oyston MBBS}

Anesthesiologist, The Scarborough Hospital, and Founder of Stop Smoking for Safer Surgery, Toronto, Ont.

\section{Reference}

1. Schultz ASH, Finegan B, Nykiforuk CIJ, et al. A qualitative investigation of smoke-free policies on hospital property. CMAJ 2011;183:E1334-44.

CMAJ 2012. DOI:10.1503/cmaj.112-2011

\section{Sudden cardiac arrest}

We appreciate Danyaal Raza's letter, ${ }^{1}$ which appeared in the Nov. 22 issue of CMAJ, regarding our paper "Socioeconomic status and incidence of sudden cardiac arrest." ${ }^{2}$ We also appreciate her suggestion that addressing low socioeconomic status itself may be instrumental in reducing mortality from sudden cardiac arrest.

Our data showed that for seven combined US and Canadian sites, the incidence of sudden cardiac arrest in the lowest socioeconomic quartile was nearly double that in the highest quartile (as measured by census tract median household income). However, we were unable to determine from our data whether low socioeconomic status itself could cause these observed higher rates of sudden cardiac arrest, or if low socioeconomic status is a marker for other factors that increase this risk.

Because we were unable to explore how low neighbourhood socioeconomic status is associated with higher rates of sudden cardiac arrest, we focused our discussion on two interventions that can be implemented immediately and are proven to increase survival from out-ofhospital sudden cardiac arrest.

We agree that addressing low socioeconomic status should be a public policy goal. As scientists, we can work toward providing better data regarding opportunities to improve health outcomes via reduction of poverty and income inequality, improved access to education, targeted education regarding disease risk factors, and improvements in promoting health in impoverished neighbourhoods.

\section{Sumeet S. Chugh MD}

Kyndaron Reinier PhD

Cedars-Sinai heart Institute, Los Angeles, Calif.

\section{References}

1. Raza D. Addressing the root cause [letter]. CMAJ 2011;183:2019.

2. Reinier K, Thomas E, Andrusiek DL, et al.; the Resuscitation Outcomes Consortium Investigators. Socioeconomic status and incidence of sudden cardiac arrest. CMAJ 2011;183:1705-1712

CMAJ 2012. DOI:10.1503/cmaj.112-2012

\section{Home-based care}

I appreciate the CMAJ news article by Erin Walkinshaw regarding the increased need for house calls by physicians. ${ }^{1}$ As a pediatrician who participates in home-based palliative care, I would add that the need extends far beyond that of doctors making house calls. Entire health systems of community-based professionals need to emerge in order to stem the flow of patients who might be better served at home to acute-care facilities. Acute care is the default for families when community care is inadequately resourced.

I am lucky to live in the only Canadian city (of which I am aware) that has 
24/7 access to pediatric nurses who are trained in pediatric palliative care. In my "black bag" there are continuous opioid infusions, central venous lines, phlebotomy supplies and treatments for seizures and hydration, to name a few items. Only within a system of continuous care in the community are patients able to stay in their homes and receive high-quality treatment for serious illness. Until we make seismic shifts in how we view health, illness and community, many of us will present to our local emergency departments for want of all kinds of care that might be better delivered at home.

\section{Dawn E. Davies MD}

Medical Director, Pediatric Palliative Care Program, Stollery Children's Hospital, Edmonton, Alta.

\section{Reference}

1. Walkinshaw E. Back to black bag and horse-andbuggy medicine. CMAJ 2011;183:1829-30.

CMAJ 2012. DOI:10.1503/cmaj.112-2013

\section{Form and function}

When Canadian researcher Dr. John R. Taylor examined foreskin under a microscope, he found specialized sensory tissue having "the rigidity and form associated with specific function.".'

The interdependence between form and function is a basic principle of biology. If by her statement in the CMAJ news article by Roger Collier ${ }^{2}$ that there are "no health benefits to having foreskin" Dr. Dinh is implying that specialized tissue of the penis has no function, then she is challenging an axiom of science.

\section{Dennis C. Harrison BSc BA}

Writer, Vancouver BC

\section{References}

1. Taylor JR, Lockwood AP, Taylor AJ. The prepuce: specialized mucosa of the penis and its loss to circumcision. Br J Urol 1996;77:291-5.

2. Collier R. Vital or vestigial? The foreskin has its fans and foes. CMAJ 2011;183:1963-4.

CMAJ 2012. DOI:10.1503/cmaj.112-2014

Some letters have been abbreviated for print. See www.cmaj.ca for full versions and competing interests. 